\title{
SÍNTESE DE PADRÕES CROMATOGRÁFICOS E ESTABELECIMENTO DE MÉTODO PARA DOSAGEM DA COMPOSIÇ̃̃O DE ÉSTERES DE ÁCIDOS GRAXOS PRESENTES NO BIODIESEL A PARTIR DO ÓLEO DE BABAÇU
}

\author{
Daniele Urioste, Matheus B. A. Castro, Francisco C. Biaggio e Heizir F. de Castro* \\ Escola de Engenharia de Lorena, Universidade de São Paulo, CP 116, 12606-970 Lorena - SP, Brasil
}

Recebido em 17/7/06; aceito em 21/6/07; publicado na web em 26/2/08

\begin{abstract}
SYNTHESIS OF CHROMATOGRAPHIC STANDARDS AND ESTABLISHMENT OF A METHOD FOR THE QUANTIFICATION OF THE FATTY ESTER COMPOSITION OF BIODIESEL FROM BABASSU OIL. Several alkyl esters were synthesized, purified, characterized by ${ }^{1} \mathrm{H}$ NMR and employed as standards for establishing chromatographic methods to monitor their formation in the synthesis of biodiesel. The efficiency of the chromatographic methods was confirmed with the products of enzymatic transesterification of babassu oil with different alcohols $\left(\mathrm{C}_{2}\right.$ to $\left.\mathrm{C}_{4}\right)$, using Lipozyme as catalyst.
\end{abstract}

Keywords: biodiesel; chromatographic standards; babassu oil.

\section{INTRODUÇÃO}

O biodiesel é definido como o derivado mono-alquil éster de ácidos graxos de cadeia longa, proveniente de fontes renováveis como óleos vegetais, cuja utilização está associada à substituição de combustíveis fósseis em motores de ciclo diesel ${ }^{1-3}$. Apresenta um potencial promissor no mundo inteiro, não só pela sua enorme contribuição ao meio ambiente, com a redução qualitativa e quantitativa dos níveis de poluição ambiental, mas também pela geração de energia renovável em substituição ao óleo diesel e outros derivados do petróleo ${ }^{1-3}$.

Vários países vêm investindo na produção e viabilização comercial do biodiesel por meio de unidades de produção com diferentes capacidades, distribuídas particularmente na Europa, América do Norte e Ásia ${ }^{4,5}$. No Brasil, a produção de biodiesel constitui um desenvolvimento prioritário, sendo que a elevação dos preços do óleo diesel e o interesse do Governo Federal em reduzir sua importação levaram o Ministério da Ciência e Tecnologia a lançar o Programa Brasileiro de Desenvolvimento Tecnológico do Biodiesel (PROBIODIESEL) (Portaria nº. 702 do MCT, de 30 de outubro de 2002).

O programa tem como objetivo fomentar a produção e utilização do biodiesel no País, de modo a se atingir sua viabilidade técnica, sócio-ambiental e econômica, prevendo o uso comercial de misturas com 5\% de biodiesel e 95\% de óleo diesel (mistura B5), esperando-se para 2010 o aumento da participação do biodiesel para 10\% (B10) e até 2020 para 20\% (B20) .

Dentre as matérias-primas mais utilizadas figuram os óleos de soja, babaçu, mamona e dendê e alguns tipos de óleos de fritura, como aqueles derivados do processamento industrial de alimentos para refeições industriais ${ }^{1,2,5}$. Visando reduzir a elevada viscosidade dos óleos vegetais, diferentes alternativas têm sido consideradas, tais como diluição, microemulsão com metanol ou etanol, decomposição térmica, craqueamento catalítico e reação de transesterificação com álcool de cadeia curta ${ }^{3,5}$. Entre essas, a transesterificação é a melhor escolha ${ }^{2,5}$. Nessa opção o metanol é o álcool predominantemente utilizado, sendo este processo adotado em inúmeros países. No Brasil, alguns grupos de pesquisa e pe-

\footnotetext{
*e-mail: heizir@dequi.eel.usp.br
}

quenos produtores também utilizam a via metílica para produção de biodiesel ${ }^{2,3}$. Entretanto, o uso do metanol, um álcool tóxico, venenoso e de origem fóssil (derivado do petróleo) é uma das grandes desvantagens desse processo. Além disso, aproximadamente 50\% do metanol consumido no país é importado. Uma alternativa interessante seria a utilização do etanol obtido da cana-de-açúcar, que é 100\% renovável e garante maior segurança na manipulação devido a sua menor toxicidade. Destaca-se ainda que, no Brasil, existe uma maior disponibilidade do álcool de cana (maior produtor mundial de etanol), tornando importante a sua aplicação na produção de biodiesel. Com a evidente decadência das fontes fósseis, nenhum outro país tem porte e condições tão favoráveis quanto o Brasil para assumir a posição de um dos principais fornecedores de biocombustíveis e tecnologias limpas para o século XXI, decorrente das extensas fronteiras agrícolas e elevada produção de óleos vegetais e álcool etílico. Outros álcoois de cadeia curta, como propanol e butanol, também estão sendo pesquisados como alternativas na transesterificação de óleos vegetais ${ }^{3,6,7}$.

A confirmação da reação de transesterificação é freqüentemente monitorada pela formação de glicerol, principal subproduto formado na reação de síntese de biodiesel ${ }^{8}$. Este subproduto é determinado por diversos métodos analíticos e o cálculo da conversão é efetuado considerando que a concentração máxima de glicerol obtido na reação é da ordem de $10 \%$ em massa do óleo utilizado ${ }^{8,9}$. No entanto, é recomendável que o monitoramento de uma reação seja efetuado tomando por base a formação do produto principal, neste caso específico, ésteres de ácidos graxos ${ }^{3}$. Para tanto, são utilizadas as técnicas de cromatografia em camada delgada, cromatografia líquida de alta eficiência; cromatografia em fase gasosa e ressonância magnética nuclear de próton ( RMN $\left.{ }^{1} \mathrm{H}\right)$. Entre esses métodos, a cromatografia de fase gasosa ${ }^{3}$ pode ser considerada uma ferramenta muito eficaz na determinação da composição do biodiesel em termos de ésteres de ácidos graxos, mesmo para amostras contendo baixos teores ${ }^{10}$. A limitação do método é a caracterização individual dos monoésteres formados, que depende da aquisição de inúmeros padrões cromatográficos que, quando disponíveis comercialmente, apresentam custo elevado.

Neste contexto, o presente trabalho teve por objetivo produzir padrões cromatográficos (ésteres de ácidos graxos) para quantificar com maior precisão a formação de ésteres obtidos na 
transesterificação enzimática de óleos vegetais com álcoois de cadeia curta (etanol, propanol e butanol). Foram preparados ésteres, tomando como referência a composição em ácidos graxos presentes no óleo de babaçu. A aplicação dessa técnica permitiu separar quantitativamente os ésteres existentes no biodiesel produzido por transesterificação do óleo de babaçu com álcoois de cadeia curta.

\section{PARTE EXPERIMENTAL}

\section{Materiais}

Os experimentos foram realizados com óleo de babaçu fornecido pela Cognis (São Paulo, Brasil) tendo a seguinte composição em ácidos graxos (em m/v): 3,5\% octanóico, 4,5\% decanóico, 44,7\% láurico, 17,5\% mirístico, 9,7\% palmítico, 3,1\% esteárico, 15,2\% oleico e 1,8\% linoleico e massa molecular média de 709,90 g/mol. $\mathrm{Na}$ síntese dos padrões cromatográficos (monoésteres de ácidos graxos) foram utilizados os ácidos graxos presentes na composição do óleo de babaçu: octanóico (Vetec), decanóico (Riedel-de Haën), mirístico, palmítico, esteárico (Merk) e oleico (Reagen). Como álcoois foram utilizados etanol $(99,5 \%$, Vetec), propanol (99,5\%, Reagen) e butanol (99,5\%, Merck). Foram também utilizados outros reagentes, como cloreto de tionila ( $\mathrm{SOCl}_{2}$ Merck), tolueno (Merck), heptano P.A. (Labsynth), hexano P.A. (Labsynth), etilenoglicol 50\% (Merck), hidróxido de sódio (Merck), periodato de sódio (Nuclear) e ácido sulfúrico P.A. (Isofar). Como catalisador da reação de transesterificação foi utilizada uma preparação comercial de lipase (Lipozyme $\mathrm{IM}^{20}, 24 \mathrm{BIU} / \mathrm{g}$ ) gentilmente doada pela Novozymes (Dinamarca). Lipozyme IM $^{20}$ é uma lipase de Rhizomucor miehei imobilizada por adsorção em uma resina de troca aniônica macroporosa (tamanho de partícula de 0,2 a 0,6 mm). Essa preparação de lipase é classificada como 1,3-específica e termo-estável, podendo ser usada em temperaturas entre $30-70{ }^{\circ} \mathrm{C}$. No entanto, para estender a estabilidade operacional é recomendado trabalhar em temperaturas na faixa de $50-60{ }^{\circ} \mathrm{C}$. Essa preparação de lipase pode ser usada em meio livre de solvente ou na presença de solventes biocompatíveis.

\section{Equipamento}

Para a análise dos monoésteres de ácido graxo empregou-se um cromatógrafo de fase gasosa Varian - Modelo CG 3800 equipado com uma coluna de aço inoxidável 5\% DEGS em Chromosorb WHP, 80/100 mesh (Hewlett Packard, Palo Alto, EUA) e detector de ionização em chama (FID). A temperatura do detector foi fixada em $230{ }^{\circ} \mathrm{C}$ e a do injetor em $190{ }^{\circ} \mathrm{C}$. Nitrogênio foi usado como gás de arraste num fluxo de $25 \mathrm{~mL} / \mathrm{min}$. Os fluxos dos gases de arraste para alimentação do detector foram: $30 \mathrm{~mL} / \mathrm{min}$ de $\mathrm{H}_{2}$ e $300 \mathrm{~mL} / \mathrm{min}$ de ar sintético.

\section{Síntese química e caracterização dos padrões cromatográficos}

As sínteses dos cloretos de ácidos foram conduzidas em reatores de $100 \mathrm{~mL}$ contendo $10 \mathrm{~g}$ de ácido graxo e 2,0 equivalentegramas de $\mathrm{SOCl}_{2}$ por $24 \mathrm{~h}$ sob agitação magnética de $200 \mathrm{rpm}$ a 25 ${ }^{\circ} \mathrm{C}$. O SOCl${ }_{2}$ residual foi removido por evaporação a vácuo e, em seguida, foram adicionados ao meio 5,0 equivalente-gramas de álcool (EtOH, PrOH ou ButOH). A esterificação foi efetuada sob agitação magnética $(200 \mathrm{rpm})$ a $25{ }^{\circ} \mathrm{C}$ por $24 \mathrm{~h}^{11}$. O HCl formado durante a reação e o álcool residual foram removidos do meio reacional por evaporação a vácuo. Os ésteres de ácidos graxos foram purificados por destilação sob pressão reduzida e suas estruturas químicas confirmadas pela análise de ressonância magnética nuclear de próton $\left(\mathrm{RMN}{ }^{1} \mathrm{H}\right)$. Os espectros foram obtidos no aparelho Varian modelo Mercury $300 \mathrm{MHz}$. Os deslocamentos químicos ( $\delta)$ foram referenciados pelo sinal do TMS (Tetrametilsilano $-\delta=$ 0 ) em solvente $\mathrm{CDCl}_{3}$. Cada espectro foi analisado calculando-se a integração dos números relativos de hidrogênio presente na estrutura química do monoéster de ácido em 0,00-6,00 ppm.

\section{Preparo das soluções padrão e curvas de calibração}

Os padrões obtidos foram diluídos em hexano $(20 \mathrm{~g} / \mathrm{L})$ e injetados individualmente no cromatógrafo para determinação do tempo de retenção de cada composto e ajuste das condições de operação do aparelho, com relação à temperatura de coluna e vazão do gás de arraste. A partir desses dados, os métodos foram calibrados com a injeção de $1 \mu \mathrm{L}$ da mistura dos ésteres diluídos em hexano contendo álcool n-hexílico (10 g/L) como padrão interno. As curvas de calibração para os ésteres foram obtidas por regressão linear, plotando-se a área do analito/área do padrão interno versus concentração do analito utilizando o software Varian Star 4.5. Os coeficientes de correlação obtidos foram próximos da unidade. Após a calibração do método, realizaram-se injeções de soluções padrão em concentrações conhecidas, para determinar a reprodutibilidade da análise cromatográfica.

\section{Reações de transesterificação por via enzimática}

As reações foram conduzidas em reatores fechados com capacidade de $50 \mathrm{~mL}$, acoplados a condensadores, contendo 12,0 g de substrato composto por álcool e óleo de babaçu, sem adição de solventes, em uma razão mássica de álcool:óleo igual a 1. As misturas foram incubadas com Lipozyme na proporção de $7 \%(\mathrm{~m} / \mathrm{m})$ em relação à massa total dos reagentes envolvidos no meio reacional. Os experimentos foram realizados na faixa de temperatura de 40 a $50{ }^{\circ} \mathrm{C}$, dependendo do sistema reacional, conforme anteriormente estabelecido ${ }^{12}$. As reações foram conduzidas por um período máximo de 96 h, sob agitação magnética de $150 \mathrm{rpm}$. Amostras foram retiradas em intervalos periódicos de $24 \mathrm{~h}$, diluídas em heptano e submetidas à análise por cromatografia de fase gasosa para quantificação dos monoésteres formados. $\mathrm{O}$ rendimento $\mathrm{R}^{7}$ foi definido como o valor que expressa a massa total obtida de ésteres $\left(\mathrm{M}_{\mathrm{t}}\right)$ em relação à massa teórica esperada $\left(\mathrm{M}_{\mathrm{e}}\right) . \mathrm{M}_{\mathrm{e}}$ foi determinada a partir da massa de ácidos graxos presentes na massa inicial do óleo de babaçu $\left(\mathrm{M}_{0}\right)$, da massa molecular correspondente a cada ácido $\left(\mathrm{MM}_{\mathrm{a}}\right)$ e do éster correspondente $\left(\mathrm{MM}_{\mathrm{e}}\right)$. Este cálculo é representado pela Equação 1a. $\mathrm{M}_{0}$ corresponde ao produto da concentração mássica para cada ácido graxo $\left(\mathrm{C}_{\mathrm{a}}\right)$, com a massa inicial de óleo utilizada (Mi) (Equação 1b). O rendimento foi calculado utilizando a massa total de ésteres obtida pela análise por cromatografia gasosa (Mt) pela massa teórica dos ésteres (Me), conforme mostrado na Equação 1c.

$$
M e=\frac{(M o \cdot M M e)}{M M a} \text { (a) } \quad M o=C a \cdot M i \quad \text { (b) } \quad R=\frac{M t}{M e} \times 100 \text { (c) (1) }
$$

\section{RESULTADOS E DISCUSSÃO}

Para quantificar com precisão os ésteres formados na transesterificação dos óleos vegetais com álcoois de cadeia curta, optou-se por sintetizar os padrões cromatográficos (ésteres de ácidos graxos) por via química, tomando como referência a composição em ácidos graxos presentes no óleo de babaçu. Desta forma, os ésteres de etila, propila e butila foram preparados por esterificação química do cloreto de acila com álcool e, em seguida, purificados 
por destilação à pressão reduzida.

As estruturas dos monoésteres purificados foram confirmadas pela análise de ressonância magnética nuclear de próton (RMN $\left.{ }^{1} \mathrm{H}\right)$. Nas Tabelas 1 a 3 são identificados os sinais de deslocamento verificados para cada estrutura química.
A injeção individual no cromatógrafo de cada padrão obtido experimentalmente gerou cromatogramas com apenas um pico revelando tratar-se de padrões altamente puros, o que era esperado em função da eficiente técnica de purificação empregada (destilação à pressão reduzida). Os tempos de retenção e as condições estabelecidas

Tabela 1, Análise dos espectros obtidos para os monoésteres de etila

\begin{tabular}{|c|c|}
\hline Espectros & Análises das estruturas \\
\hline Octanoato de etila & $\begin{array}{l}\mathrm{RMN}{ }^{1} \mathrm{H}\left(\mathrm{CDCl}_{3}, \delta, 300 \mathrm{~Hz}, \mathrm{C}_{10} \mathrm{H}_{20} \mathrm{O}_{2}\right): 4,20-3,98(\mathrm{q}, 2 \mathrm{H}) ; 2,34-2,22(\mathrm{t}, 2 \mathrm{H}) ; 1,75-1,54(\mathrm{~m}, 2 \mathrm{H}) ; \\
1,35-1,21(\mathrm{~m}, 11 \mathrm{H}) ; 0,96-0,81(\mathrm{t}, 3 \mathrm{H})\end{array}$ \\
\hline Laurato de etila & $\begin{array}{l}\mathrm{RMN}{ }^{1} \mathrm{H}\left(\mathrm{CDCl}_{3}, \delta, 300 \mathrm{~Hz}, \mathrm{C}_{14} \mathrm{H}_{28} \mathrm{O}_{2}\right): 4,18-4,05(\mathrm{q}, 2 \mathrm{H}) ; 2,35-2,25(\mathrm{t}, 2 \mathrm{H}) ; 1,69-1,54(\mathrm{~m}, 2 \mathrm{H}) \\
1,33-1,22(\mathrm{~m}, 19 \mathrm{H}) ; 0,96-0,84(\mathrm{t}, 3 \mathrm{H})\end{array}$ \\
\hline Miristato de etila & $\begin{array}{l}\mathrm{RMN}{ }^{1} \mathrm{H}\left(\mathrm{CDCl}_{3}, \delta, 300 \mathrm{~Hz}, \mathrm{C}_{16} \mathrm{H}_{32} \mathrm{O}_{2}\right): 4,22-4,05(\mathrm{q}, 2 \mathrm{H}) ; 2,35-2,17(\mathrm{t}, 2 \mathrm{H}) ; 1,74-1,57(\mathrm{~m}, 2 \mathrm{H}) \\
1,38-1,22(\mathrm{~m}, 23 \mathrm{H}) ; 0,98-0,84(\mathrm{t}, 3 \mathrm{H})\end{array}$ \\
\hline Palmitato de etila & $\begin{array}{l}\mathrm{RMN}{ }^{1} \mathrm{H}\left(\mathrm{CDCl}_{3}, \delta, 300 \mathrm{~Hz}, \mathrm{C}_{18} \mathrm{H}_{36} \mathrm{O}_{2}\right): 4,24-4,04(\mathrm{q}, 2 \mathrm{H}) ; 2,37-2,22(\mathrm{t}, 2 \mathrm{H}) ; 1,91-1,39(\mathrm{~m}, 2 \mathrm{H}) \\
1,36-1,20(\mathrm{~m}, 27 \mathrm{H}) ; 0,95-0,83(\mathrm{t}, 3 \mathrm{H})\end{array}$ \\
\hline Estearato de etila & $\begin{array}{l}\mathrm{RMN}{ }^{1} \mathrm{H}\left(\mathrm{CDCl}_{3}, \delta, 300 \mathrm{~Hz}, \mathrm{C}_{20} \mathrm{H}_{40} \mathrm{O}_{2}\right): 4,15-4,04(\mathrm{q}, 2 \mathrm{H}) ; 2,30-2,20(\mathrm{t}, 2 \mathrm{H}) ; 1,78-1,44(\mathrm{~m}, 2 \mathrm{H}) \\
1,41-0,93(\mathrm{~m}, 31 \mathrm{H}) ; 0,89-0,82(\mathrm{t}, 3 \mathrm{H})\end{array}$ \\
\hline Oleato de etila & $\begin{array}{l}\mathrm{RMN}{ }^{1} \mathrm{H}\left(\mathrm{CDCl}_{3}, \delta, 300 \mathrm{~Hz}, \mathrm{C}_{20} \mathrm{H}_{38} \mathrm{O}_{2}\right): 5,50-5,17(\mathrm{~m}, 2 \mathrm{H}) ; 4,20-4,01(\mathrm{q}, 2 \mathrm{H}) ; 2,32-2,21(\mathrm{t}, 2 \mathrm{H}) ; \\
2,17-1,75(\mathrm{~m}, 4 \mathrm{H}) ; 1,74-1,44(\mathrm{~m}, 2 \mathrm{H}) ; 1,42-1,04(\mathrm{~m}, 23 \mathrm{H}) ; 0,92-0,78(\mathrm{t}, 3 \mathrm{H})\end{array}$ \\
\hline
\end{tabular}

Tabela 2, Análise dos espectros obtidos para os monoésteres de propila

\begin{tabular}{ll}
\hline Espectros & \multicolumn{1}{c}{ Análises das estruturas } \\
\hline Octanoato de propila & $\mathrm{RMN}{ }^{1} \mathrm{H}\left(\mathrm{CDCl}_{3}, \mathrm{~d}, 300 \mathrm{~Hz}, \mathrm{C}_{11} \mathrm{H}_{22} \mathrm{O}_{2}\right): 4,05-3,97(\mathrm{t}, 2 \mathrm{H}) ; 2,31-2,23(\mathrm{t}, 2 \mathrm{H}) ; 1,68-1,56(\mathrm{~m}, 4 \mathrm{H}) ;$ \\
& $1,32-1,15(\mathrm{~m}, 8 \mathrm{H}) ; 0,96-0,85(2 \mathrm{t}, 6 \mathrm{H})$ \\
& $\mathrm{RMN}{ }^{1} \mathrm{H}\left(\mathrm{CDCl}_{3}, \mathrm{~d}, 300 \mathrm{~Hz}, \mathrm{C}_{13} \mathrm{H}_{26} \mathrm{O}_{2}\right): 4,07-3,98(\mathrm{t}, 2 \mathrm{H}) ; 2,35-2,25(\mathrm{t}, 2 \mathrm{H}) ; 1,72-1,57(\mathrm{~m}, 4 \mathrm{H}) ;$ \\
& $1,34-1,19(\mathrm{~m}, 12 \mathrm{H}) ; 0,98-0,84(2 \mathrm{t}, 6 \mathrm{H})$
\end{tabular}

Tabela 3. Análise dos espectros obtidos para os monoésteres de butila

\begin{tabular}{ll}
\hline Espectros & \multicolumn{1}{c}{ Análises das estruturas } \\
\hline Octanoato de butila & $\mathrm{RMN}{ }^{1} \mathrm{H}\left(\mathrm{CDCl}_{3}, \mathrm{~d}, 300 \mathrm{~Hz}, \mathrm{C}_{12} \mathrm{H}_{24} \mathrm{O}_{2}\right): 4,10-4,05(\mathrm{t}, 2 \mathrm{H}) ; 2,33-2,27(\mathrm{t}, 2 \mathrm{H}) ; 1,62-1,55(\mathrm{~m}, 4 \mathrm{H}) ;$ \\
& $1,34-1,26(\mathrm{~m}, 10 \mathrm{H}) ; 0,92-0,83(2 \mathrm{t}, 6 \mathrm{H})$ \\
Decanoato de butila & $\mathrm{RMN}{ }^{1} \mathrm{H}\left(\mathrm{CDCl}_{3}, \mathrm{~d}, 300 \mathrm{~Hz}, \mathrm{C}_{14} \mathrm{H}_{28} \mathrm{O}_{2}\right): 4,08-4,01(\mathrm{t}, 2 \mathrm{H}) ; 2,29-2,23(\mathrm{t}, 2 \mathrm{H}) ; 1,62-1,53(\mathrm{~m}, 4 \mathrm{H}) ;$ \\
& $1,31-1,18(\mathrm{~m}, 14 \mathrm{H}) ; 0,93-0,81(2 \mathrm{t}, 6 \mathrm{H})$ \\
Laurato de butila & $\mathrm{RMN}{ }^{1} \mathrm{H}\left(\mathrm{CDCl}_{3}, \mathrm{~d}, 300 \mathrm{~Hz}, \mathrm{C}_{16} \mathrm{H}_{32} \mathrm{O}_{2}\right): 4,10-4,00(\mathrm{t}, 2 \mathrm{H}) ; 2,31-2,24(\mathrm{t}, 2 \mathrm{H}) ; 1,68-1,54(\mathrm{~m}, 4 \mathrm{H}) ;$ \\
& $1,38-1,18(\mathrm{~m}, 18 \mathrm{H}) ; 0,95-0,83(2 \mathrm{t}, 6 \mathrm{H})$ \\
Miristato de butila & $\mathrm{RMN}{ }^{1} \mathrm{H}\left(\mathrm{CDCl}_{3}, \mathrm{~d}, 300 \mathrm{~Hz}, \mathrm{C}_{18} \mathrm{H}_{36} \mathrm{O}_{2}\right): 4,10-4,05(\mathrm{t}, 2 \mathrm{H}) ; 2,33-2,27(\mathrm{t}, 2 \mathrm{H}) ; 1,62-1,55(\mathrm{~m}, 4 \mathrm{H}) ;$ \\
& $1,34-1,26(\mathrm{~m}, 18 \mathrm{H}) ; 0,92-0,83(2 \mathrm{t}, 6 \mathrm{H})$ \\
Palmitato de butila & $\mathrm{RMN}{ }^{1} \mathrm{H}\left(\mathrm{CDCl}_{3}, \mathrm{~d}, 300 \mathrm{~Hz}, \mathrm{C}_{20} \mathrm{H}_{40} \mathrm{O}_{2}\right): 4,08-4,02(\mathrm{t}, 2 \mathrm{H}) ; 2,31-2,25(\mathrm{t}, 2 \mathrm{H}) ; 1,65-1,57(\mathrm{~m}, 4 \mathrm{H}) ;$ \\
& $1,33-1,15(\mathrm{~m}, 26 \mathrm{H}) ; 0,96-0,83(2 \mathrm{t}, 6 \mathrm{H})$ \\
Estearato de butila & $\mathrm{RMN}{ }^{1} \mathrm{H}\left(\mathrm{CDCl}_{3}, \mathrm{~d}, 300 \mathrm{~Hz}, \mathrm{C}_{22} \mathrm{H}_{44} \mathrm{O}_{2}\right): 4,08-4,02(\mathrm{t}, 2 \mathrm{H}) ; 2,30-2,24(\mathrm{t}, 2 \mathrm{H}) ; 1,66-1,54(\mathrm{~m}, 4 \mathrm{H}) ;$ \\
& $1,46-1,07(\mathrm{~m}, 20 \mathrm{H}) ; 0,95-0,82(2 \mathrm{t}, 6 \mathrm{H})$ \\
Oleato de butila & $\mathrm{RMN}{ }^{1} \mathrm{H}\left(\mathrm{CDCl}, \mathrm{d}, 300 \mathrm{~Hz}, \mathrm{C}_{22} \mathrm{H}_{42} \mathrm{O}_{2}\right): 5,40-5,28(\mathrm{~m}, 2 \mathrm{H}) ; 4,09-4,02(\mathrm{t}, 2 \mathrm{H}) ; 2,31-2,25(\mathrm{t}, 2 \mathrm{H}) ;$ \\
& $2,17-1,81(\mathrm{~m}, 4 \mathrm{H}) ; 1,66-1,58\left(\mathrm{~m}_{4}, 4 \mathrm{H}\right) ; 1,38-1,19(\mathrm{~m}, 22 \mathrm{H}) ; 0,96-0,84(2 \mathrm{t}, 6 \mathrm{H})$
\end{tabular}


Tabela 4. Determinação dos tempos de retenção para cada composto presente nas amostras padrões de mistura de monoésteres

\begin{tabular}{lcccccc}
\hline & \multicolumn{2}{c}{$\begin{array}{c}\text { Monoésteres de etila } \\
\text { Tempo de retenção } \\
(\mathrm{min})\end{array}$} & $\begin{array}{c}\text { Concentração } \\
(\mathrm{g} / \mathrm{L})\end{array}$ & $\begin{array}{c}\text { Monoésteres de propila } \\
\text { Tempo de retenção } \\
(\mathrm{min})\end{array}$ & $\begin{array}{c}\text { Concentração } \\
(\mathrm{g} / \mathrm{L})\end{array}$ & $\begin{array}{c}\text { Momoésteres de butila } \\
(\mathrm{min})\end{array}$ \\
\hline $\mathrm{PI}$ & 1,67 & 10,80 & 0,90 & 10,80 & 0,76 & 10,80 \\
$\mathrm{C}_{8}$ & 2,27 & 20,26 & 1,50 & 21,30 & 1,35 & 16,76 \\
$\mathrm{C}_{10}$ & 4,57 & 15,90 & 2,87 & 21,28 & 2,35 & 20,22 \\
$\mathrm{C}_{12}$ & 10,19 & 20,58 & 5,97 & 19,38 & 4,42 & 21,88 \\
$\mathrm{C}_{14}$ & 13,22 & 23,80 & 11,35 & 20,38 & 8,79 & 23,24 \\
$\mathrm{C}_{16}$ & 16,72 & 24,82 & 14,27 & 22,82 & 16,39 & 23,52 \\
$\mathrm{C}_{18}$ & 22,40 & 21,56 & 19,01 & 22,14 & 21,18 & 23,28 \\
$\mathrm{C}_{18: 1}$ & 23,85 & 24,60 & 20,03 & 22,50 & 21,90 & 24,56 \\
\hline
\end{tabular}

PI: Padrão Interno

Tabela 5. Condições de operação do cromatógrafo para os métodos de dosagem dos monoésteres

\begin{tabular}{|c|c|}
\hline Método & Programa de aquecimento da coluna \\
\hline Monoésteres de etila & $\begin{array}{l}\text { Rampa de aquecimento } 90{ }^{\circ} \mathrm{C} \text { por } 2 \mathrm{~min} \text { até } 130{ }^{\circ} \mathrm{C} \text { em uma taxa de } 25^{\circ} \mathrm{C} / \text { min, mantendo-se } \\
\text { constante por } 9 \mathrm{~min} \text {, até } 160^{\circ} \mathrm{C} \text { numa taxa de } 35^{\circ} \mathrm{C} / \mathrm{min} \text { mantendo-se constante por } 11 \mathrm{~min} \text {; } \\
\text { totalizando } 25 \mathrm{~min} \text { de análise. }\end{array}$ \\
\hline Monoésteres de propila & $\begin{array}{l}\text { Rampa de aquecimento } 120^{\circ} \mathrm{C} \text { por } 10 \mathrm{~min} \text { até } 170{ }^{\circ} \mathrm{C} \text { em uma taxa de } 30{ }^{\circ} \mathrm{C} / \mathrm{min} \text {, mantendo- } \\
\text { se constante por } 9 \mathrm{~min} \text {; totalizando } 25 \mathrm{~min} \text { de análise. }\end{array}$ \\
\hline Monoésteres de butila & $\begin{array}{l}\text { Rampa de aquecimento } 150^{\circ} \mathrm{C} \text { por } 15 \mathrm{~min} \text { até } 180^{\circ} \mathrm{C} \text { em uma taxa de } 30^{\circ} \mathrm{C} / \mathrm{min} \text {, mantendo- } \\
\text { se constante por } 9 \mathrm{~min} \text {; totalizando } 25 \mathrm{~min} \text { de análise. }\end{array}$ \\
\hline
\end{tabular}

em termos de regulagem do aparelho quanto aos programas de aquecimento da coluna para cada método de análise estão resumidos nas Tabelas 4 e 5, respectivamente. As Figuras 1a, b, c ilustram os cromatogramas gerados nos métodos estabelecidos para determinação das concentrações em ésteres de etila, propila e butila, respectivamente. A avaliação estatística da recuperação e reprodutibilidade dos métodos estabelecidos é mostrada na Tabela 6.

Tabela 6. Avaliação estatística da recuperação e da reprodutibilidade dos métodos cromatográficos

\begin{tabular}{lccc}
\hline Composto & $\begin{array}{c}\text { Concentração Concentração } \\
\text { Injetada } \\
(\mathrm{g} / \mathrm{L})\end{array}$ & $\begin{array}{c}\text { Recuperada } \\
(\mathrm{g} / \mathrm{L})\end{array}$ & Recuperação \\
\hline Caprilato de etila & 20,26 & $19,98 \pm 0,38$ & 98,62 \\
Decanoato de etila & 15,90 & $15,84 \pm 0,27$ & 99,62 \\
Laurato de etila & 20,58 & $20,85 \pm 0,29$ & 101,31 \\
Miristato de etila & 23,80 & $23,80 \pm 0,22$ & 100,00 \\
Palmitato de etila & 24,82 & $24,95 \pm 0,27$ & 100,52 \\
Estearato de etila & 21,56 & $21,75 \pm 0,29$ & 100,88 \\
Oleato de etila & 24,60 & $24,86 \pm 0,12$ & 101,06 \\
& & & \\
Caprilato de propila & 21,30 & $21,16 \pm 0,19$ & 99,34 \\
Decanoato de propila & 21,28 & $21,31 \pm 0,32$ & 100,14 \\
Laurato de propila & 19,38 & $19,40 \pm 0,27$ & 100,10 \\
Miristato de propila & 20,38 & $20,48 \pm 0,20$ & 100,50 \\
Palmitato de propila & 22,82 & $23,02 \pm 0,15$ & 100,87 \\
Estearato de propila & 22,14 & $22,29 \pm 0,20$ & 100,67 \\
Oleato de propila & 22,50 & $22,60 \pm 0,16$ & 100,44 \\
& & & \\
Caprilato de butila & 16,76 & $16,71 \pm 0,14$ & 99,70 \\
Decanoato de butila & 20,22 & $20,02 \pm 0,15$ & 99,01 \\
Laurato de butila & 21,88 & $21,78 \pm 0,21$ & 99,54 \\
Miristato de butila & 23,24 & $23,38 \pm 0,12$ & 100,60 \\
Palmitato de butila & 23,52 & $23,70 \pm 0,10$ & 100,76 \\
Estearato de butila & 23,28 & $23,33 \pm 0,25$ & 100,21 \\
Oleato de butila & 24,56 & $24,32 \pm 0,28$ & 99,02 \\
\hline
\end{tabular}

A metodologia desenvolvida foi validada pela quantificação dos ésteres formados na reação de transesterificação enzimática do óleo de babaçu com álcoois de cadeia curta empregando Lipozyme $\mathrm{IM}^{20}$ como catalisador. Optou-se pela utilização de um catalisador comercial com características conhecidas amplamente descritas na literatura ${ }^{13}$, incluindo comportamento e desempenho em diversas modificações de óleos e gorduras ${ }^{14}$, principalmente no que se refere a modificações visando a obtenção de biodiesel ${ }^{8}$.

O perfil de formação dos monoésteres para cada sistema reacional (óleo:álcool) em função do tempo de reação é mostrado nas Figuras 2a, b, c, tomando por base os dados gerados na execução dos respectivos métodos. O rendimento de transesterificação, bem como a produtividade de cada sistema reacional (Figura 3) foram calculados nos tempos de reação que forneceram a concentração mais elevada dos diversos monoésteres.

De maneira geral, para os três álcoois testados houve formação de todos os monoésteres de ácidos graxos presentes no óleo de babaçu em concentrações diretamente proporcionais ao tamanho da cadeia do álcool, ou seja, quanto maior o tamanho da cadeia do álcool maior a concentração dos diversos monoésteres. Conforme esperado, as concentrações mais elevadas de monoésteres formados foram referentes aos ésteres laurato, tendo em vista que o óleo de babaçu tem em sua composição 44,7\% de ácido láurico.

Os resultados obtidos indicam também uma influência do tamanho da cadeia do álcool no rendimento de reação. Para o sistema óleo e etanol, a máxima concentração dos diferentes monoésteres foi alcançada após $96 \mathrm{~h}$ de reação, fornecendo um rendimento global de $68,12 \%$ em monoésteres de etila. Rendimentos superiores foram alcançados para o sistema óleo e propanol, da ordem de 93,20\% em 96 h. O sistema óleo/butanol foi o que forneceu comparativamente o maior rendimento para todos os monoésteres, sendo obtido um rendimento global de 97,43\% em $72 \mathrm{~h}$.

O baixo rendimento obtido para o sistema empregando etanol como doador do grupo acila pode ser atribuído à elevada polaridade desse álcool, que pode ocasionar danos na estrutura da enzima, resultando 
em uma inibição parcial ou total da preparação enzimática. Essa hipótese pode ser reforçada quando se leva em consideração que a preparação de enzima (Lipozyme) tem caráter hidrofílico, sendo suscetível aos fenômenos de partição (migração) do álcool para a fase sólida (enzima/suporte), resultando numa saturação do microambiente da enzima. Desta forma, a água contida na preparação enzimática pode ter sido parcialmente removida, ocorrendo redução da atividade da lipase. Além disso, pode ocorrer uma redução da disponibilidade do álcool na fase líquida interrompendo a reação de transesterificação. Assim, os fenômenos de partição causam a modificação do estado original de hidratação enzimática e um aparente desequilíbrio entre a taxa de conversão e disponibilidade do álcool no meio reacional.

\section{CONCLUSÃO}

A elaboração dos métodos de análise cromatográfica a partir dos padrões previamente sintetizados revelou ser uma ferramenta importante no monitoramento do progresso da reação de transesterificação enzimática de óleos vegetais com álcoois de cadeia curta $(\mathrm{EtOH}, \mathrm{PrOH}$ e ButOH). A análise tem uma duração máxima de 25 min, contrastando com a duração das reações enzimáticas que são essencialmente lentas. Desta forma, a quantificação individual dos ésteres formados permite não só calcular a conversão e a seletividade da reação durante o processo, como também facilita possíveis correções operacionais no sistema reacional, como por exemplo, ajuste do teor de água, adições programadas de equivalentes de álcool, entre outros.
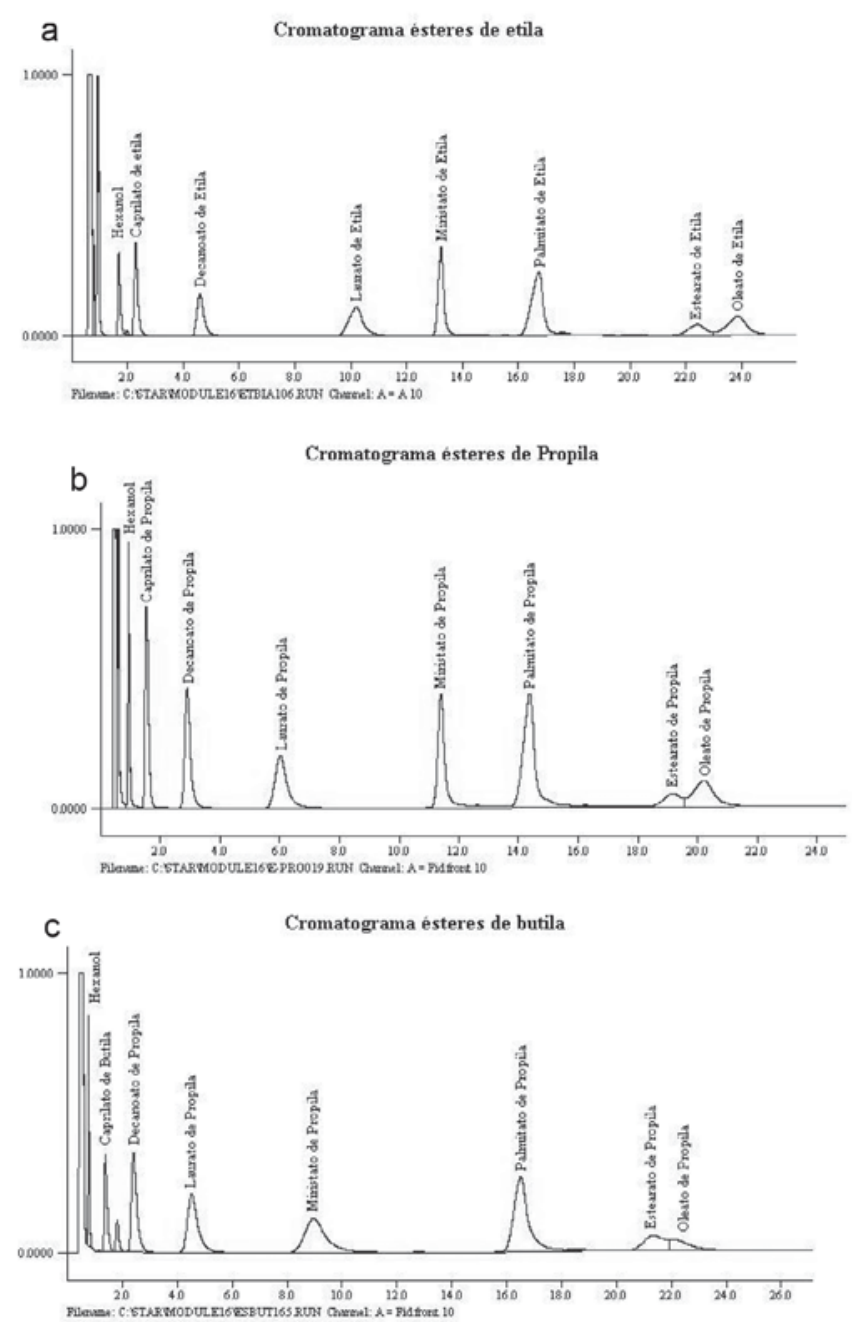

Figura 1. Cromatogramas gerados nas análises dos monoésteres de etila, propila e butila empregando os métodos cromatográficos estabelecidos
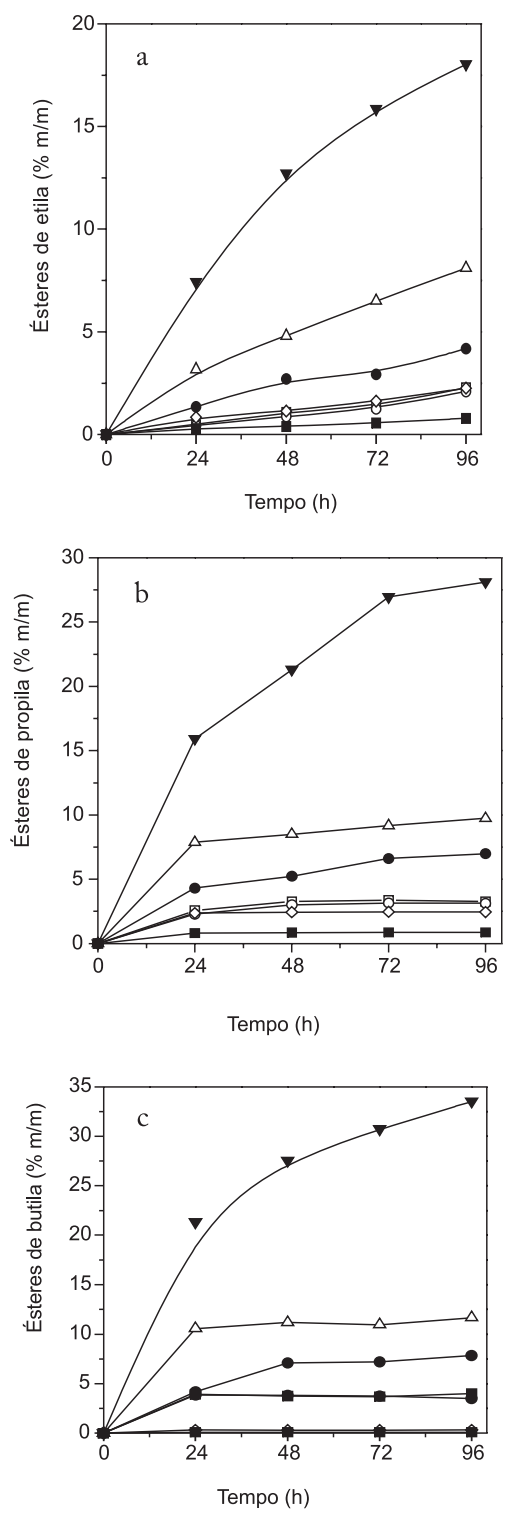

Figura 2. Formação dos monoésteres de etila $(A)$, propila $(B)$ e butila $(C)$ na reação de transesterificação enzimática do óleo de babaçu com etanol (40 $\left.{ }^{\circ} \mathrm{C}\right)$, propanol $\left(45^{\circ} \mathrm{C}\right)$ e butanol $\left(50^{\circ} \mathrm{C}\right)$ catalisada por Lipozyme. Símbolos: $\left(C_{8}\right), \bigcirc\left(C_{10}\right), \nabla\left(C_{12}\right), \triangle\left(C_{14}\right), \diamond\left(C_{16}\right), \mathbf{\square}\left(C_{18}\right), \bullet\left(C_{18: 1}\right)$

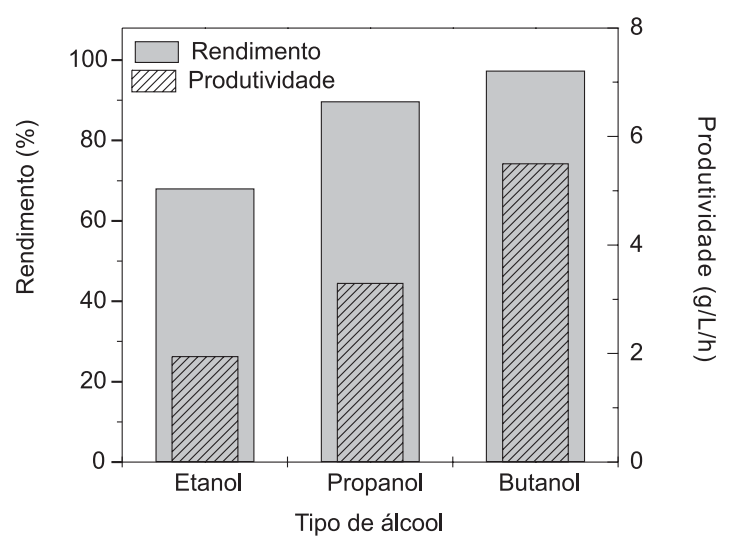

Figura 3. Rendimentos globais e produtividades nas reações de transesterificação do óleo de babaçu com diferentes álcoois catalisada por Lipozyme 


\section{AGRADECIMENTOS}

Ao apoio financeiro concedido pela CAPES e CNPq (Processo Universal No. 472980/ 2003).

\section{REFERENCIAS}

1. Costa Neto, P. R.; Luciano F. S.; Rossi, L. F. S.; Zagonel, G. F.; Ramos, L. P.; Quim. Nova 2000, 23, 531.

2. Schuchardt, U.; Sercheli, R.; Vargas, R. M.; J. Braz. Chem. Soc. 1998, 9, 199.

3. Pinto, A. C.; Guarieiro, L. L. N.; Rezende, M. J. C.; Ribeiro, N. M.; Torres, E. A.; Lopes, W. A.; Pereira, P. A. P.; de Andrade, J. B.; J. Braz. Chem. Soc. 2005, 16, 1313.

4. Knothe, G.; Steidley, K. R.; Energy Fuels 2005, 19, 1192.
5. Ramos, L. P.; Kucek, K. T.; Domingos, A. K.; Wilhelm, H. M.; Rev. Biotecnol. Ciênc. Desenv. 2003, 31, 28.

6. Ma, F.; Hanna, M. A.; Bioresour. Technol. 1999, 70, 1.

7. Paula, A, V.; Urioste, D.; Santos, C. J.; de Castro, H. F.; J. Chem. Technol. Biotechnol. 2007, 82, 281

8. Oliveira, D.; Oliveira, J. V.; Faccio, C.; Menoncim, S.; Amroginsk, C.; Ciênc. Tecnol. Aliment. 2004, 24, 178

9. Karinen, R. S.; Krause, A. O. I.; Appl. Catal., A 2006, 306, 128.

10. Foglia, T. A.; Jones, K. C.; Nunez, A.; Phillips, J. G.; Mittelbach, M.; Chromatographia 2004, 60, 305.

11. Ratke, M. W.; Deitch, J.; Tetrahedron Lett. 1971, 31, 2953.

12. Urioste, D.; Dissertação de Mestrado, Faculdade de Engenharia Química de Lorena, Brasil, 2004, disponível; http/www.faenquil.br

13. de Castro, H. F.; Anderson, W. A.; Quim. Nova 1995, 16, 544

14. de Castro, H. F.; Mendes, A. A.; Santos, J. C.; Aguiar, C. L.; Quim. Nova 2004, 27, 146. 